\title{
Aerosol composition and sources during the Chinese Spring Festival: fire- works, secondary aerosol, and holiday effects
}

\section{Q. Jiang et al.}

Correspondence to: Y. L. Sun (sunyele@ mail.iap.ac.cn) 

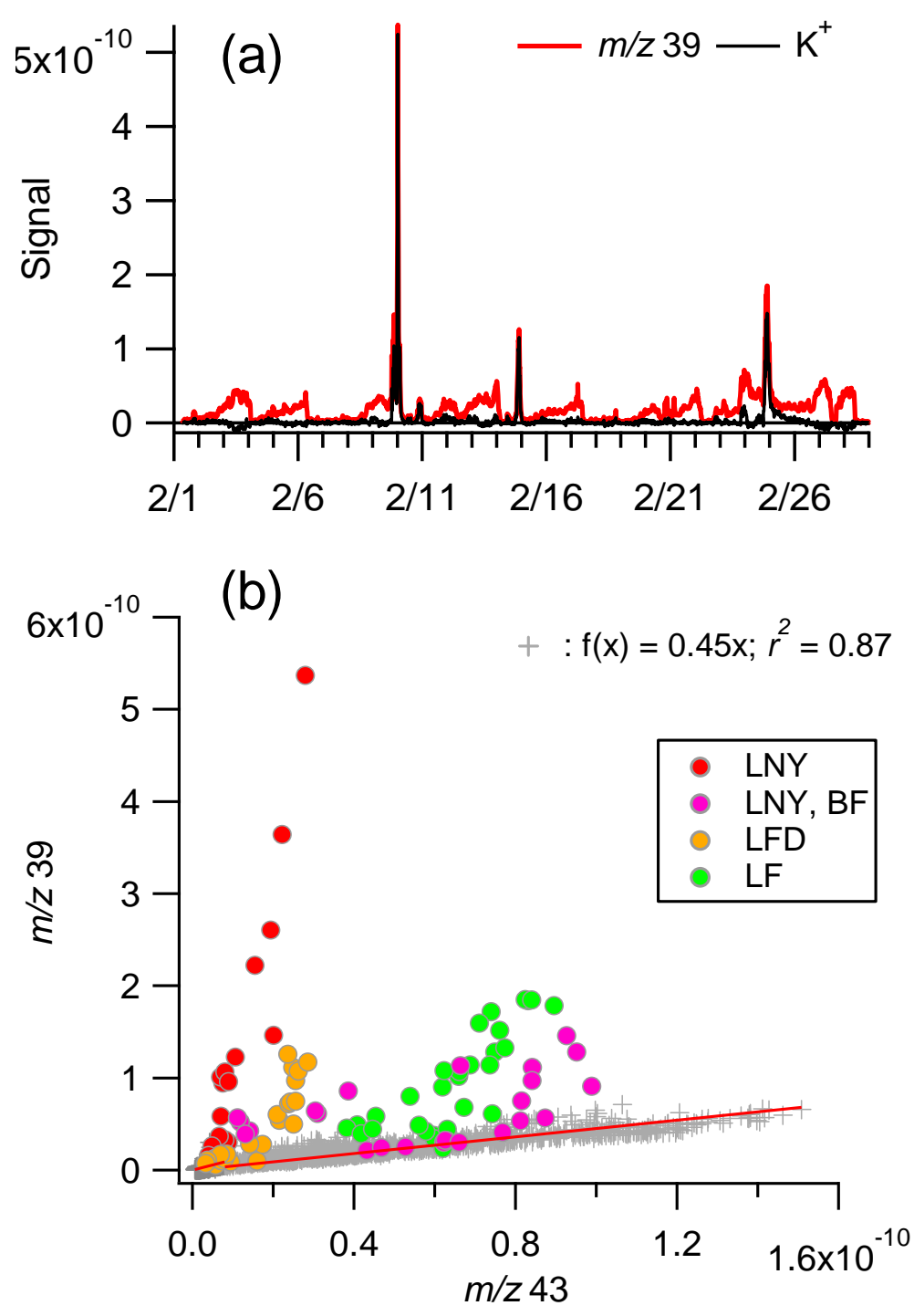

22 Fig. S1. (a) Time series of signals of $\mathrm{m} / \mathrm{z} 39$ and $\mathrm{K}^{+}$, (b) correlation of $\mathrm{m} / \mathrm{z} 39 \mathrm{vs} . \mathrm{m} / \mathrm{z}$ 23 43. The data in (b) are segregated into three FW events, i.e., Lunar New Year (LNY), 24 Lunar Fifth Day (LFD), and Lantern Festival (LF), and NFW periods. The data during 25 the FW period of 18:00 - 23:30, 9 February (LNY, BF) that have large influences of 26 NFW sources are also shown for a comparison. The $\mathrm{K}^{+}$signal in (a) was calculated as $27 \mathrm{~m} / \mathrm{z} 39-\mathrm{m} / \mathrm{z} 43 \times(\mathrm{m} / \mathrm{z} 39 / 43)_{\mathrm{NFW}}$, i.e., $m / z 39-m / z 43 \times 0.45$. 

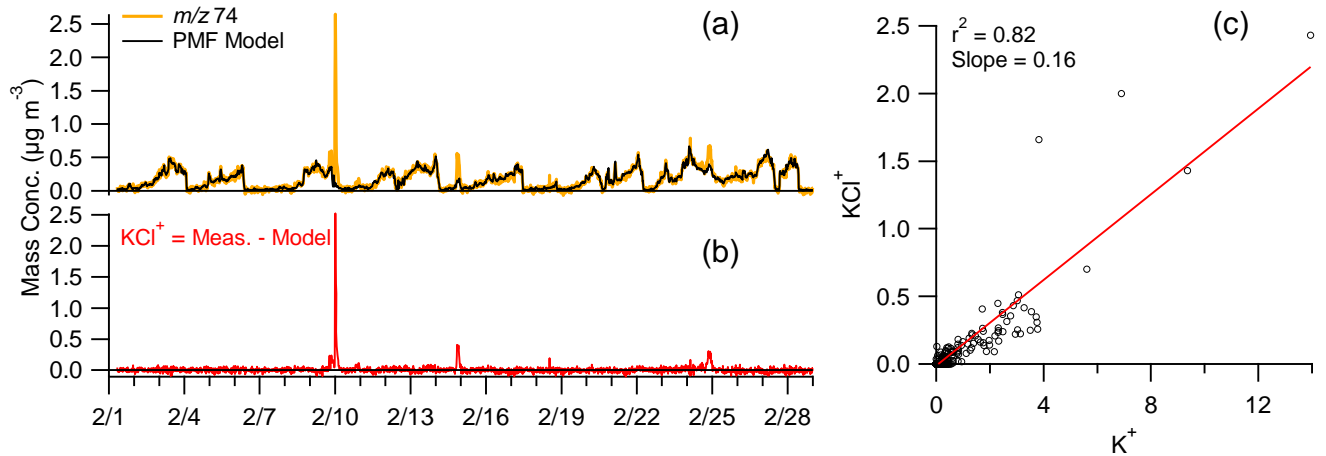

29 Fig. S2. Time series of (a) measured and PMF modeled $\mathrm{m} / \mathrm{z} 74$, (b) the difference

30 between measured and modeled $\mathrm{m} / \mathrm{z} 74$. The PMF modeled $\mathrm{m} / \mathrm{z} 74$ refers to the sum of $31 \mathrm{~m} / \mathrm{z} 74$ in four OA factors, i.e., HOA, COA, CCOA, and OOA. (c) shows the 32 correlation plot of $\mathrm{KCl}^{+}$versus $\mathrm{K}^{+}$. 

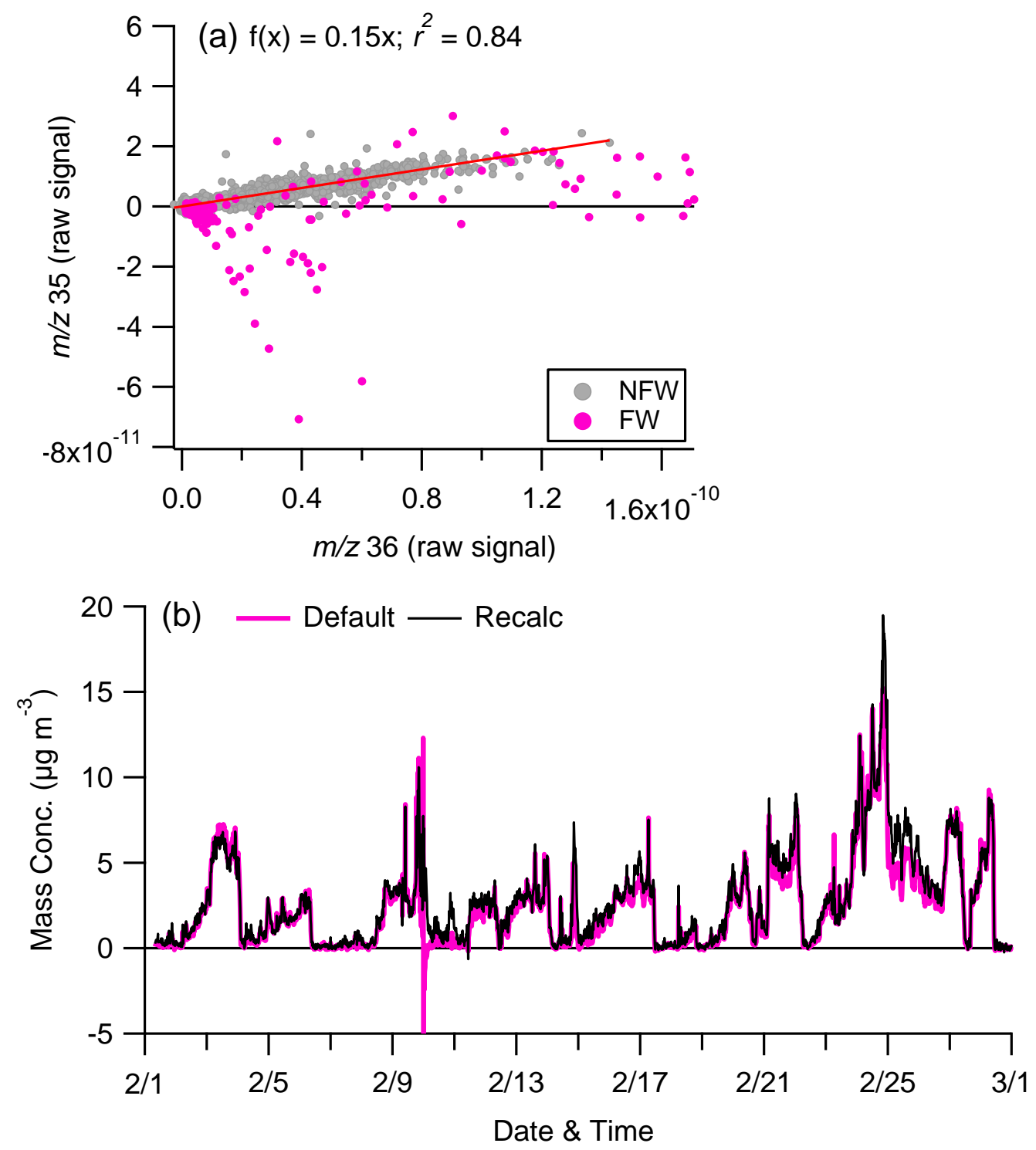

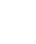

Fig. S3. (a) Correlation of $m / z 35$ vs. $m / z 36$ during FW and NFW periods, (b) Time series of the default chloride analyzed by the ACSM standard software and the recalculated chloride using the corrected ${ }^{35} \mathrm{Cl}^{+}$and ${ }^{37} \mathrm{Cl}^{+}$, which is ${ }^{35} \mathrm{Cl}^{+}=m / z 36 \times$ 0.15 and ${ }^{37} \mathrm{Cl}^{+}=0.323 \times{ }^{35} \mathrm{Cl}^{+}$. 


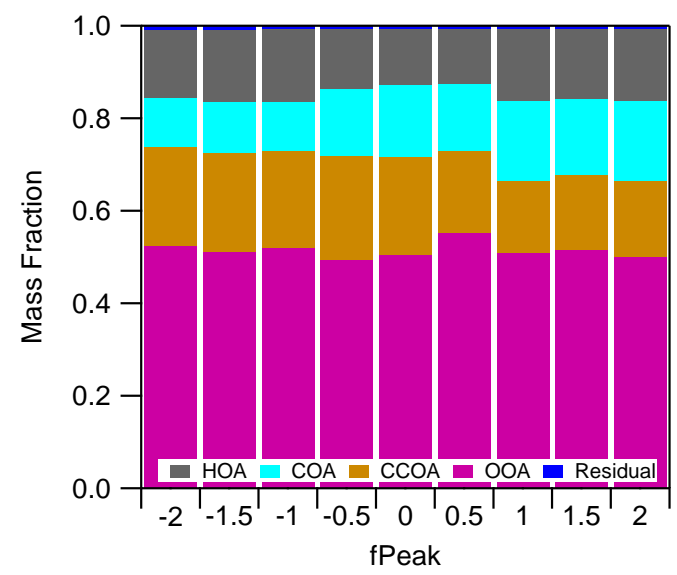

39

Fig. S4. Mass fraction of four OA factors (from 6-factor solution; three OOA factors were combined into one OOA factor as discussed in the text) as a function of fpeak values. Overall, the contribution of each OA factor was relatively stable across different fpeak values (average $\pm 1 \sigma$; $\min -\max )$ : HOA $(14 \pm 1.6 \% ; 12-16 \%)$; COA $(14 \pm 2.8 \% ; 11-17 \%)$; CCOA $(19 \pm 2.7 \% ; 15-22 \%)$; OOA $(51 \pm 1.7 ; 49-55 \%)$.
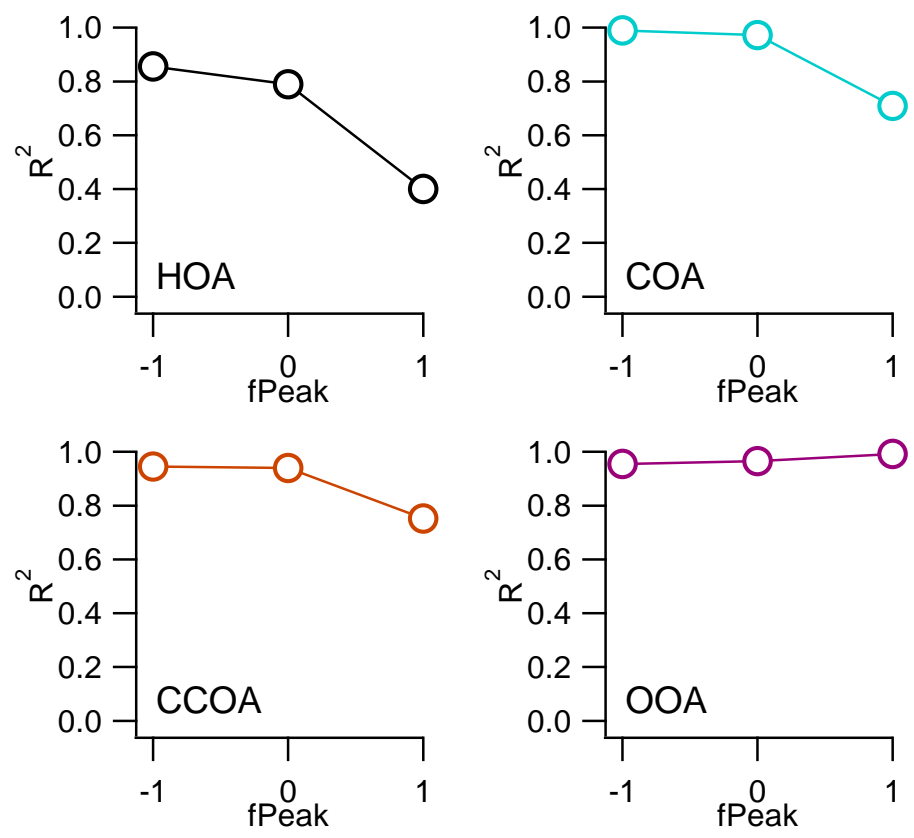

Fig. S5. Mass spectra correlations between this study and those identified in Beijing in winter 2011-2012 (Sun et al., 2013). The mass spectra of OA factors at fpeak =-1 presented the best correlation with those identified in winter 2011-2012 (Sun et al., 2013). Therefore, four factor solution with fpeak $=-1$ was chosen in this study. 


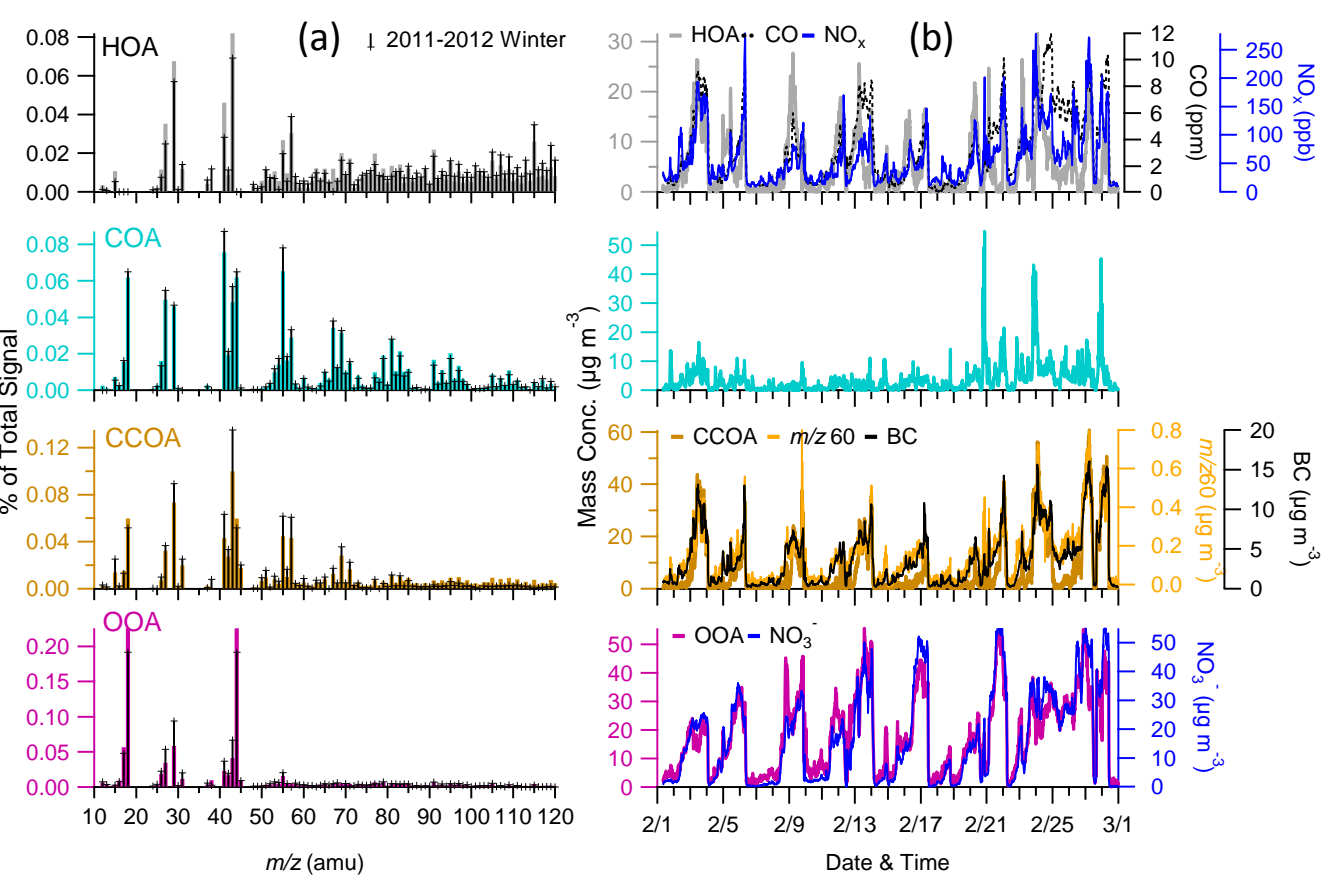

51 Fig. S6. (a) Mass spectraand (b) time series of the four OA components, i.e., HOA, 52 COA, CCOA, and OOA. The comparisons of mass spectra of four OA factors with 53 those resolved during winter 2011-2012 (Sun et al., 2013) are shown in (a), and the 54 comparisons of the time series of four OA factors with the external tracers including $55 \mathrm{CO}, \mathrm{NO}_{\mathrm{x}}, \mathrm{m} / \mathrm{z} 60, \mathrm{Chl}$, and $\mathrm{NO}_{3}$ are shown in (b).

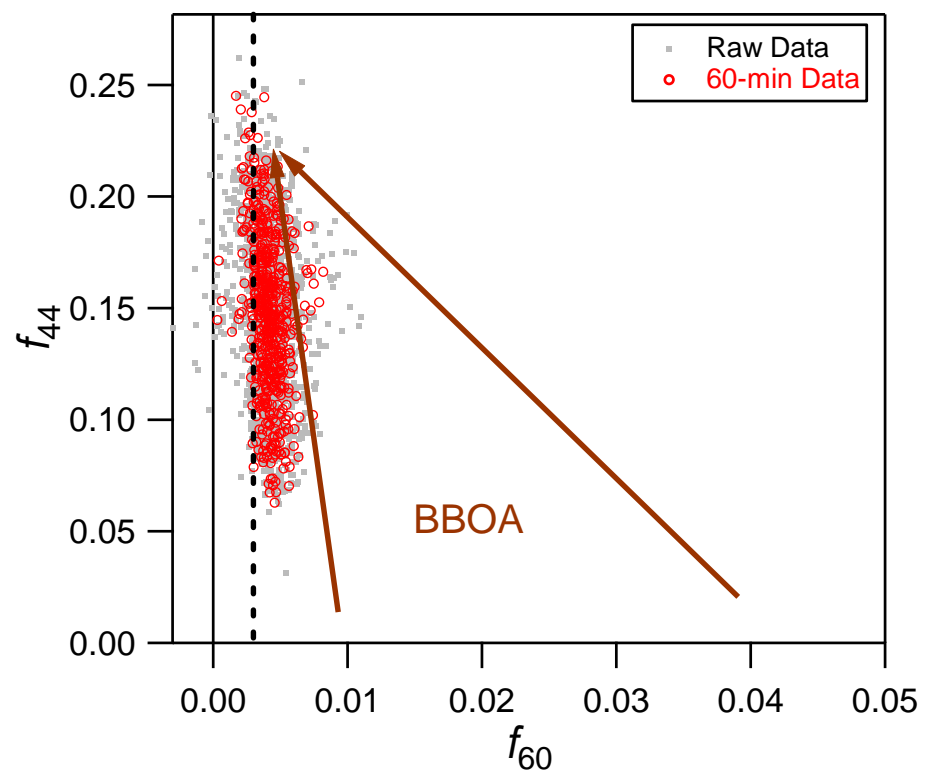


Fig. S7. Scatter plot of $\mathrm{f}_{44}$ (ratio of $\mathrm{m} / \mathrm{z} 44$ to total OA signal) versus $\mathrm{f}_{60}$ (ratio of $\mathrm{m} / \mathrm{z}$ 60 to total OA signal). Red circles represent 60 -min average data. The two arrow lines represent a typical region influenced by biomass burning (Cubison et al., 2011), and the vertical dash line shows the typical $\mathrm{f}_{60}(\sim 0.3 \%)$ in the absence of biomass burning.
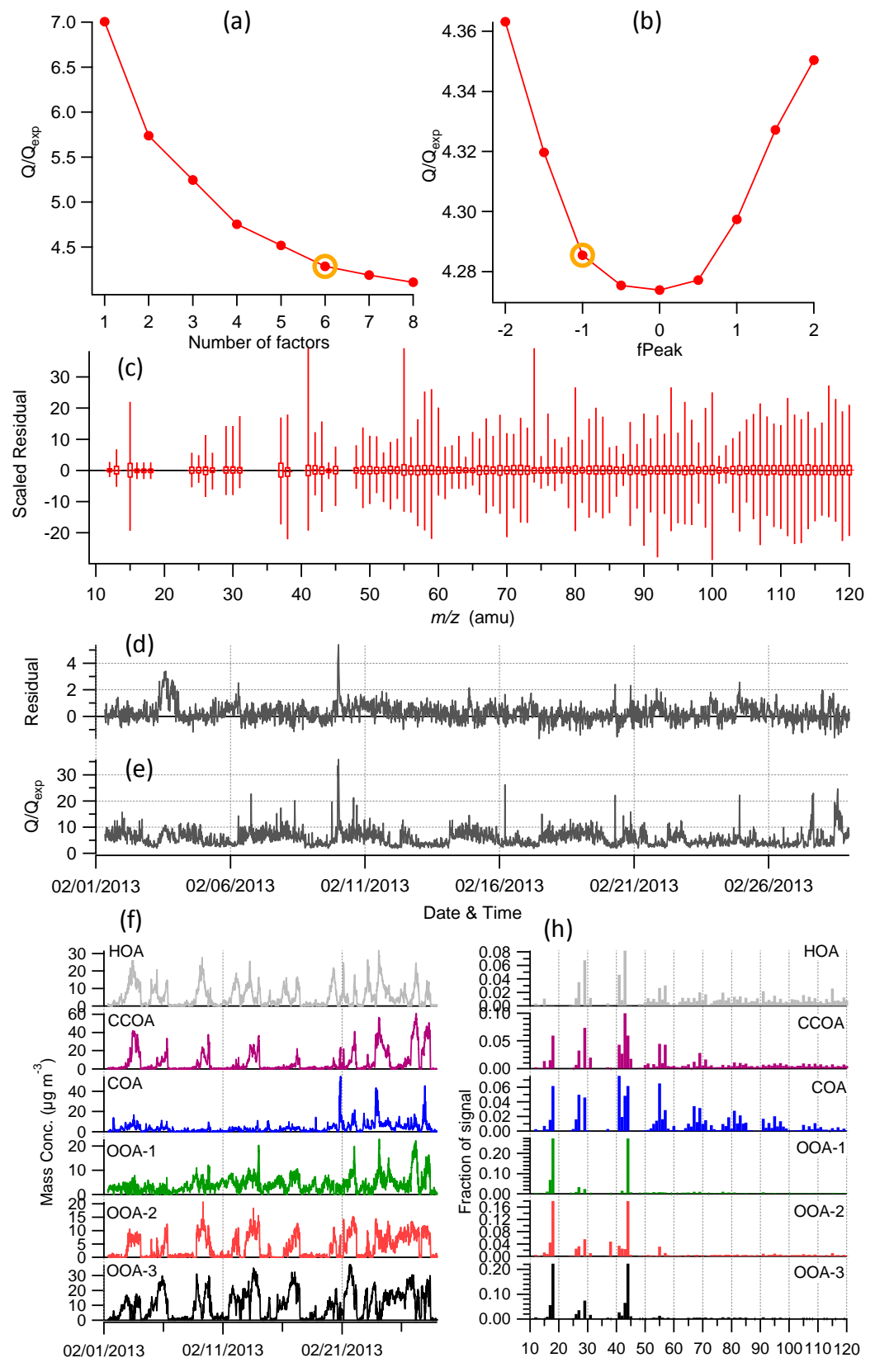

(h)

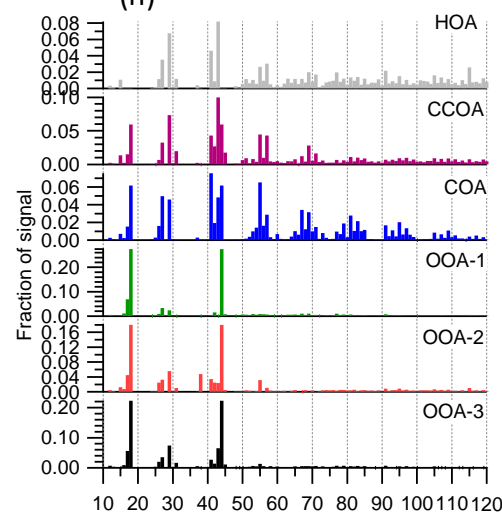

Date \& Time

$\mathrm{m} / \mathrm{z}(\mathrm{amu})$

Fig. S8. Summary of key diagnostic plots of the PMF results for 6-factor solution: (a) $\mathrm{Q} / \mathrm{Q}_{\exp }$ as a function of number of factors, (b) $\mathrm{Q} / \mathrm{Q}_{\exp }$ as a function of FPEAK, (c) the box and whiskers plot showing the distributions of scaled residuals for each $\mathrm{m} / \mathrm{z}$, (d) 
(a) shown in Figure $\mathrm{S} 4$.
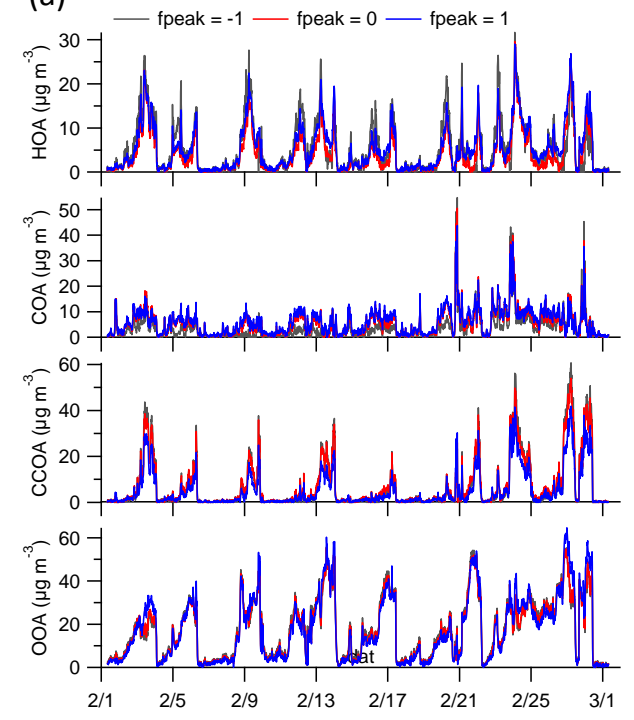

$$
\text { (a) }
$$

30

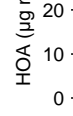

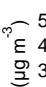

잉 20 (b)

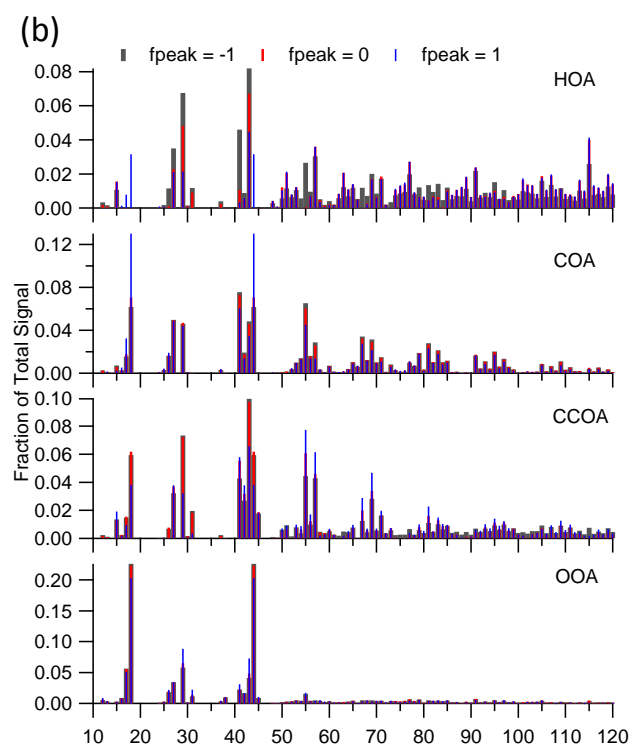

69

variations of the residual (= measured - reconstructed), (e) Q/Q $\mathrm{Q}_{\exp }$ for each point in time, ( $\mathrm{f}$ ) time series of 6 factors and $(\mathrm{h})$ factor profiles of 6 factors. The three OOA factors, i.e., OOA-1, OOA-2, and OOA-3 were combined into one OOA factor that is

Fig. S9. Time series and mass spectra of four OA factors for three different fpeak values $(-1,0$, and 1$)$. The time series of four OA factors for different fpeak values agree overall well. However, the mass spectra of OA factors have large differences.

Note that most mass spectra of OA factors at fpeak $>1$ are largely different from the standard mass spectra reported in $\mathrm{Ng}$ et al. (2011) and those resolved in Beijing in winter 2011-2012 (Sun et al., 2013). 

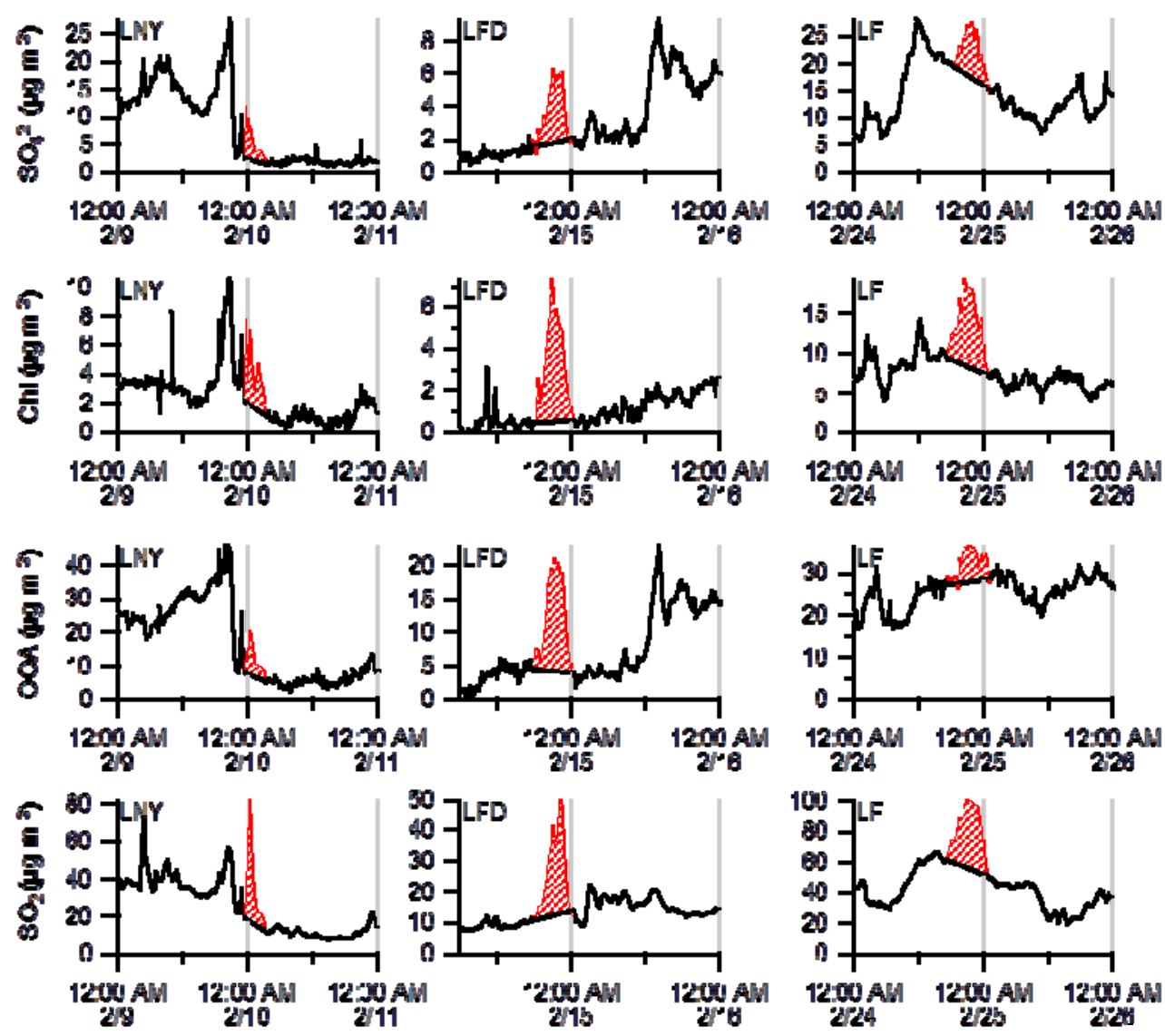

77 Fig. S10. Estimation of firework contributions (red shaded areas) for selected species $78 \quad\left(\mathrm{SO}_{4}, \mathrm{Chl}, \mathrm{OOA}\right.$, and $\left.\mathrm{SO}_{2}\right)$ during $\mathrm{LNY}, \mathrm{LFD}$, and LF. 


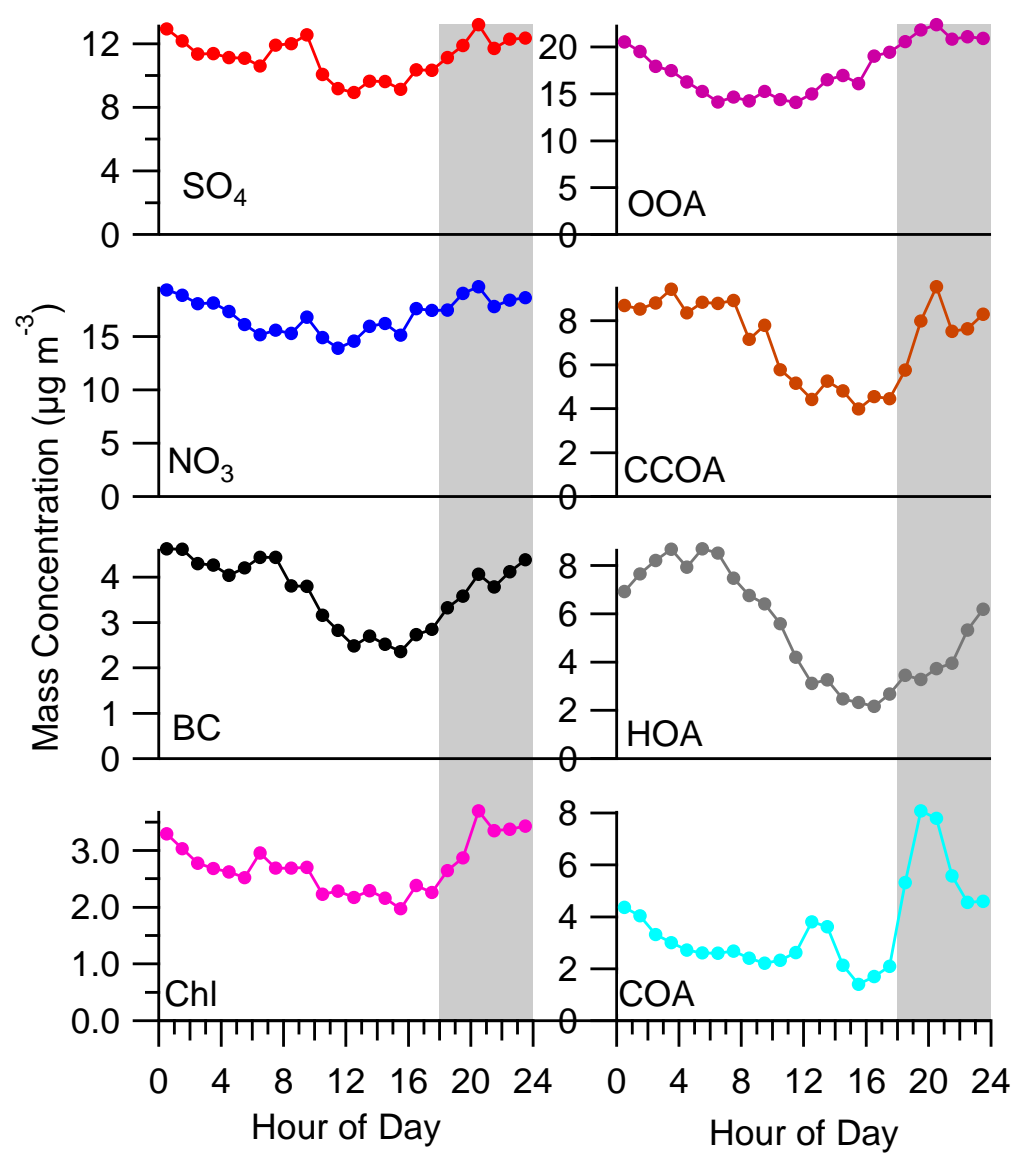

80 Fig. S11. Diurnal cycles of $\mathrm{SO}_{4}, \mathrm{NO}_{3}, \mathrm{BC}, \mathrm{Chl}, \mathrm{OOA}, \mathrm{CCOA}, \mathrm{HOA}$, and $\mathrm{COA}$ for the 81 entire study. The shaded areas show the typical time intervals with fireworks impacts. 


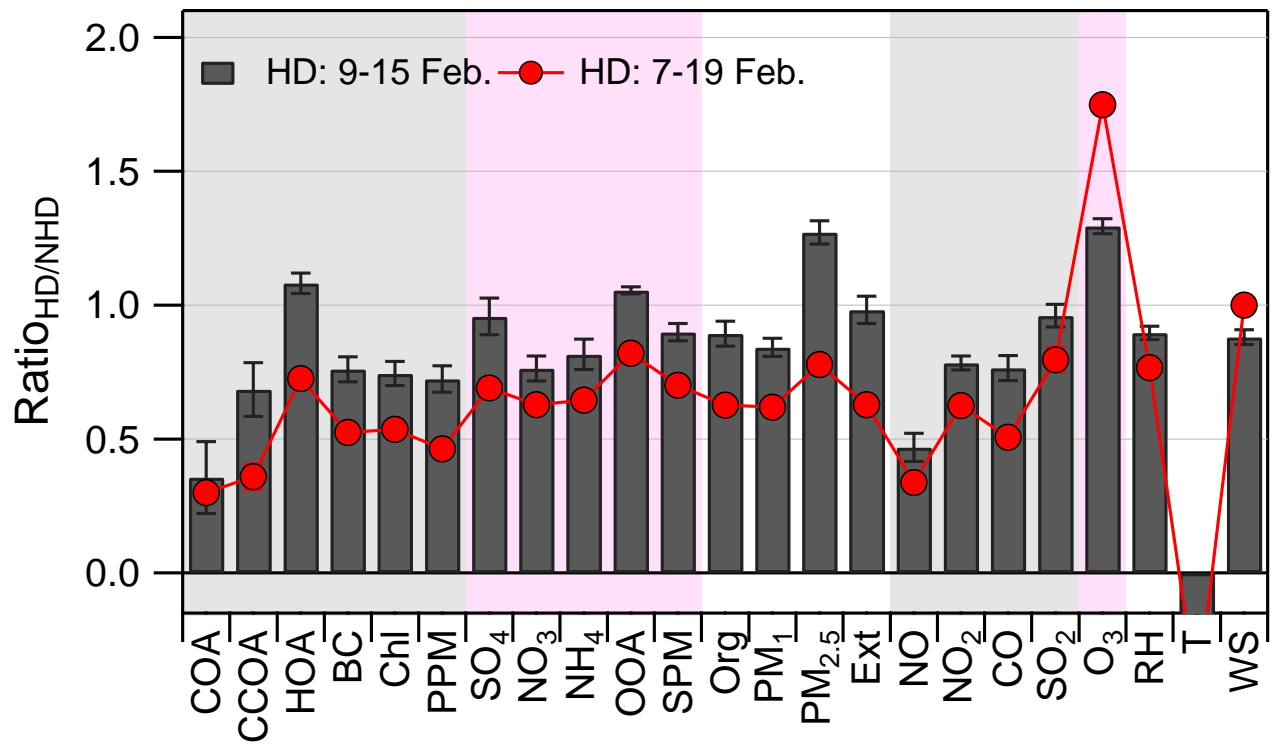

82

Fig. S12. The average ratios of aerosol species, gaseous species, PM mass concentrations, extinction coefficient, and meteorological parameters between holiday (HD) and non-holiday (NHD) periods. Two different holidays, i.e., the official holiday of $9-15$ February and the informal holiday of $7-20$ February were used for averages. Also note that the averages were made by excluding firework events during both HD and NHD days. The error bars represent the standard errors of the ratios.

\section{References}

Cubison, M. J., Ortega, A. M., Hayes, P. L., Farmer, D. K., Day, D., Lechner, M. J., Brune, W. H., Apel, E., Diskin, G. S., Fisher, J. A., Fuelberg, H. E., Hecobian, A., Knapp, D. J., Mikoviny, T., Riemer, D., Sachse, G. W., Sessions, W., Weber, R. J., Weinheimer, A. J., Wisthaler, A., and Jimenez, J. L.: Effects of aging on organic aerosol from open biomass burning smoke in aircraft and laboratory studies, Atmos. Chem. Phys., 11, 12049-12064, 10.5194/acp-11-12049-2011, 2011.

Ng, N. L., Canagaratna, M. R., Jimenez, J. L., Zhang, Q., Ulbrich, I. M., and Worsnop, D. R.: Real-Time Methods for Estimating Organic Component Mass Concentrations from Aerosol Mass Spectrometer Data, Environ. Sci. Technol., 45, 910-916, 10.1021/es102951k, 2011.

Sun, Y. L., Wang, Z. F., Fu, P. Q., Yang, T., Jiang, Q., Dong, H. B., Li, J., and Jia, J. $\mathrm{J} .:$ Aerosol composition, sources and processes during wintertime in Beijing, China, Atmos. Chem. Phys., 13, 4577-4592, 10.5194/acp-13-4577-2013, 2013. 